\title{
Perancangan Sistem Informasi Berbasis Website Pada Perkampungan Budaya Betawi Setu Babakan
}

\author{
Ridwan Ahmad Ma'arif1*, Tri Ichsan Saputra², Mohamad Dimas Radityatama², \\ Andez Apriansyah ${ }^{4}$, Nur Hayati ${ }^{5}$ \\ 1,23,4,5)Program Studi Informatika, Fakultas Teknologi Komunikasi dan Informatika, Universitas Nasional \\ Jl. Sawo Manila, Jakarta, Indonesia 12520 \\ *email: ridwan.22693@gmail.com
}

\begin{abstract}
ABSTRAK - Indonesia merupakan negara kepulauan yang mana penggunaan media internet sebagai sarana penyebaran informasi sangat berguna, sebab berbagai jenis informasi dari bagian Indonesia manapun dapat diketahui dengan mudah. Pengguna internet di Indonesia telah mencapai 150 juta pada tahun 2019 yang mana angka tersebut mengalami kenaikan 13 persen atau sekitar 17 juta dari tahun sebelumnya, kemudian rata-rata setiap hari penggunaan waktu dengan internet yaitu selama 8 jam 36 menit. Perancangan website menggunakan metode pengumpulan data dan metode waterfall sebagai metode perancangan sistem. Digunakan diagram perancangan sistem berupa UML (Unified Modeling Language) yang terdiri dari usecase diagram dan class diagram serta ERD (Entity Relationship Diagram). Website dirancang dengan menggunakan framework CodeIgniter dengan tools Visual Studio Code dan MySQL sebagai sumber basis datanya. Pengujian dalam penelitian ini menghasilkan keberhasilan 100\% dalam mengakses website diberbagai browser dan juga keberhasilan fungsi dari berbagai jenis interface yang dibangun.
\end{abstract}

Kata Kunci - CodeIgniter; Sistem Informasi; Unified Modeling Language; Waterfall; Website.

\section{Design of Website-Based Information System at Perkampungan Budaya Betawi Setu Babakan}

\begin{abstract}
Indonesia is an archipelagic country where the use of internet media as a means of disseminating information is very useful because various types of information from any part of Indonesia can be easily known. Internet users in Indonesia have reached 150 million in 2019, where the figure has increased by 13 percent or around 17 million from the previous year, then on average every day using the internet is 8 hours 36 minutes. Website design uses data collection methods and waterfall methods as a system design method. Used system design diagram in the form of UML (Unified Modeling Language) which consists of use case diagrams and class diagrams and ERD (Entity Relationship Diagram). The website is designed using the CodeIgniter framework with Visual Studio Code tools and MySQL as its database source. Testing in this study resulted in 100\% success in accessing websites in various browsers and also the success of the functions of various types of interfaces that were built.
\end{abstract}

Keywords - CodeIgniter; Information Systems; Unified Modeling Language; Waterfall; Website.

\section{Pendahuluan}

Indonesia merupakan negara kepulauan yang mana penggunaan media internet sebagai sarana penyebaran informasi sangat berguna, sebab berbagai jenis informasi dari bagian Indonesia manapun dapat diketahui dengan mudah. Bergunanya internet sebagai media penyebaran informasi dapat dilihat melalui Data Tren Internet yang mengalami kenaikan. Menurut Hootsuite, pengguna internet di Indonesia telah mencapai 150 juta pada tahun 2019 yang mana angka tersebut mengalami kenaikan $13 \%$ atau sekitar 17 juta dari tahun sebelumnya, kemudian rata-rata setiap hari penggunaan waktu dengan internet yaitu selama 8 jam 36 menit [1].

Perkampungan Budaya Betawi Setu Babakan merupakan cagar kebudayaan betawi di daerah 
Jagakarsa, Jakarta Selatan [2]. Saat kami datang untuk melihat perayaan atau atau acara kebudayaan betawi disana, jumlah pengunjung yang datang untuk melihat acara tersebut tergolong sedikit dan terlihat jelas bahwa mayoritas dari pengunjung berasal dari kawasan sekitar lokasi. Hal tersebut dikarenakan kurangnya informasi masyarakat luas khususnya di Jakarta akan acara tersebut atau mungkin mereka belum mengetahui lokasi tersebut.

Dengan memanfaatkan peningkatan jumlah penggunaan internet di Indonesia, maka membangun website guna menyebarluaskan kebudayaan betawi yang ada di Jakarta kepada masyarakat Indonesia maupun mancanegara sangat berguna sebagai sarana edukasi mengenal lebih kebudayaan betawi diawali dengan website dan nantinya masyarakat tertarik untuk mengunjungi lokasi.

\section{METODE DAN BAHAN}

\section{A. Metode Pengumpulan Data}

Kami menggunakan metode pengumpulan data guna memenuhi kriteria yang layak dalam perancangan website dengan metode berikut ini [3] :

1) Observasi, dilakukan pengamatan dengan mendatangi lokasi yang diteliti dan juga mencari tahu kegiatan yang diselenggarakan disana.

2) Wawancara, kami melakukan proses interaksi dan komunikasi pada pihak-pihak terkait yang dapat memberikan informasi lokasi dengan rinci.

3) Dokumentasi, dengan ini kami mencari informasi-informasi yang ada kaitannya berupa dokumen dan foto.

4) Studi Pustaka, kami mengumpulkan teori-teori yang dapat membantu guna menambah informasi sebagai referensi.

\section{B. Metode Perancangan Sistem}

Dalam perancangan sistem kami menggunakan metode waterfall atau juga bisa disebut dengan metode air terjun. Model dari metode waterfall memiliki tahapan utama yang mencerminkan aktivitas pengembangan dasar [4]. Terdapat 5 (lima) tahapan pada metode waterfall, yaitu analisis, desain, implementasi, pengujian dan pemeliharaan.

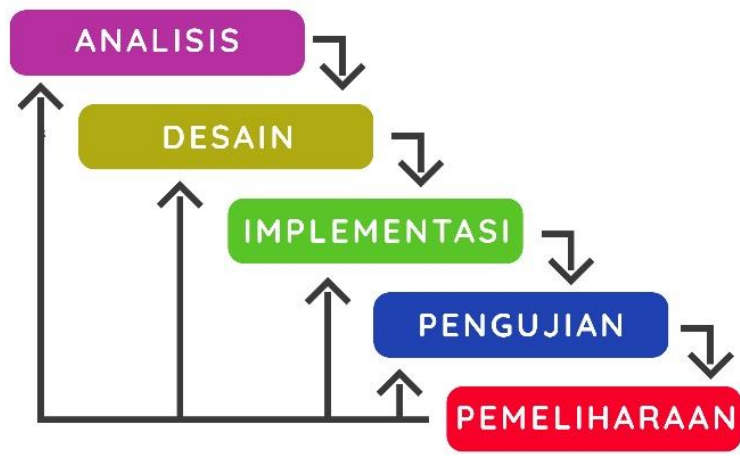

Gambar 1. Model metode waterfall

Tahapan dari model metode waterfall sudah mencerminkan proses dasar [5], diantaranya :

1) Analisis, tahap ini diperlukan komunikasi untuk memahami kebutuhan yang diperlukan oleh pengguna dan batasannya.

2) Desain, pada tahap ini akan ditentukan spesifikasi dan arsitektur sistem secara keseluruhan. Perancangan arsitektur sistem didasarkan pada hasil dari tahap sebelumnya yaitu tahap analisa.

3) Implementasi, pada tahap ini keseluruhan dari desain sistem yang telah dibuat sebelumnya akan diubah menjadi program yang nantinya akan menjadi sebuah sistem yang sesuai dengan kebutuhan yang telah disepakati. Kemudian unit pengujian akan memverifikasi bahwa apakah sistem sudah sesuai dengan kebutuhan yang diperlukan atau tidak.

4) Pengujian, pada tahap ini sistem yang sudah dibuat dalam tahap implementasi akan diintegrasikan dan diuji untuk menguji kesesuaian sistem yang telah dirancang.

5) Pemeliharaan, tahap akhir dalam metode ini yaitu sistem akan dijalankan serta dilakukan pemeliharaan guna memperbaiki kesalahan sistem yang tidak ditemukan pada langkah sebelumnya.

\section{HASIl DAN PEMbahasan}

\section{A. Analisa Kebutuhan}

Dengan analisa kebutuhan diperoleh kebutuhan pengguna dan kebutuhan sistem [6], [7].

1) Kebutuhan Pengguna, disini akan dibagi menjadi dua pengguna (user), yaitu:

a. Administrator

- Dapat menambah, mengedit serta menghapus data artikel/galeri/event.

- Dapat merespon kritik dan saran.

b. Pengunjung

- Dapat melihat artikel/galeri/event.

- Dapat memberikan kritik dan 
sarannya.

2) Kebutuhan sistem, dalam perancangan website dibutuhkan perangkat lunak (software) dan perangkat keras (hardware) [8].

a. Kebutuhan software: Visual Studio Code v1.34.0, XAMPP Control Panel v3.2.3, PHP v7.3.3, framework CodeIgniter v3.1.10 dan bootstrap v4.3.1.

b. Kebutuhan hardware: Windows 10, Intel Core i5 gen 4th, ram 8 GB, SSD 256 dan HDD 500 GB, VGA AMD R5 2 GB.

\section{B. Unified Modeling Language}

Dalam perancangan sistem digunakan UML (Unified Modeling Language) guna mempermudah pemahaman dalam penggambaran perancangan sistem [9].

1) Entity relationship Diagram

Rancangan Entity relationship diagram diperlihatkan pada Gambar 2.

\section{2) Use case Diagram}

Use case diagram pada Gambar 3. menggambarkan interaksi administrator maupun pengunjung terhadap sistem. Interaksi antara administrator dengan sistem dibutuhkan login guna memperbaharui data, kemudian interaksi yang tidak dibutuhkan login yaitu melihat website, begitupula dengan pengunjung yang tidak membutuhkan login untuk interaksi dalam website, yang dapat dilakukan oleh pengunjung yaitu melihat website dan mengirim kritik dan saran [10].

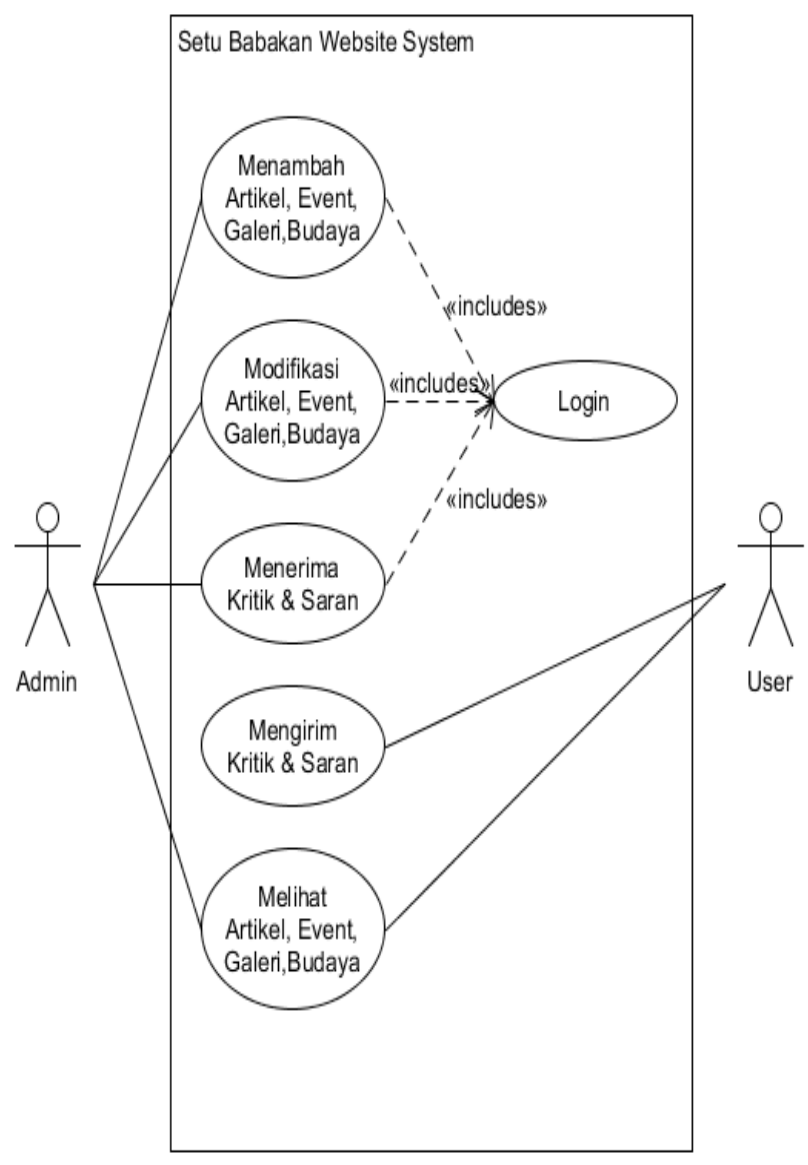

Gambar 3. Use case diagram

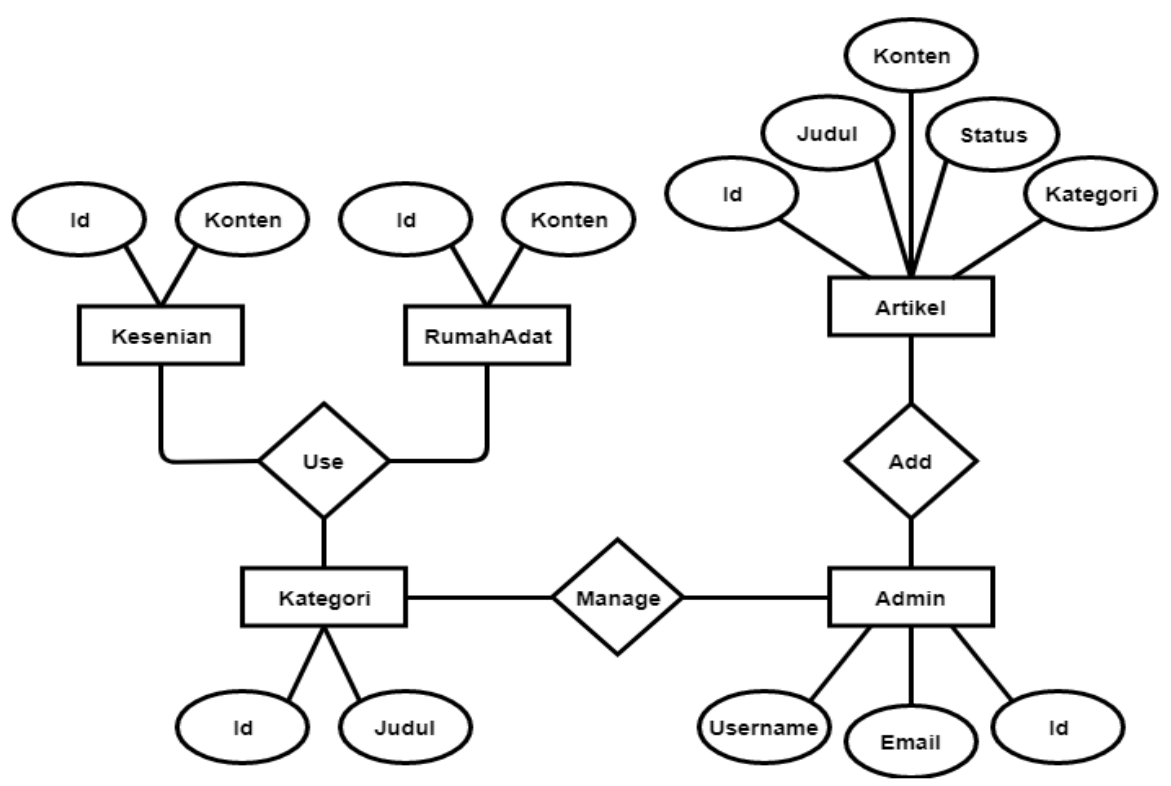

Gambar 2. ERD 


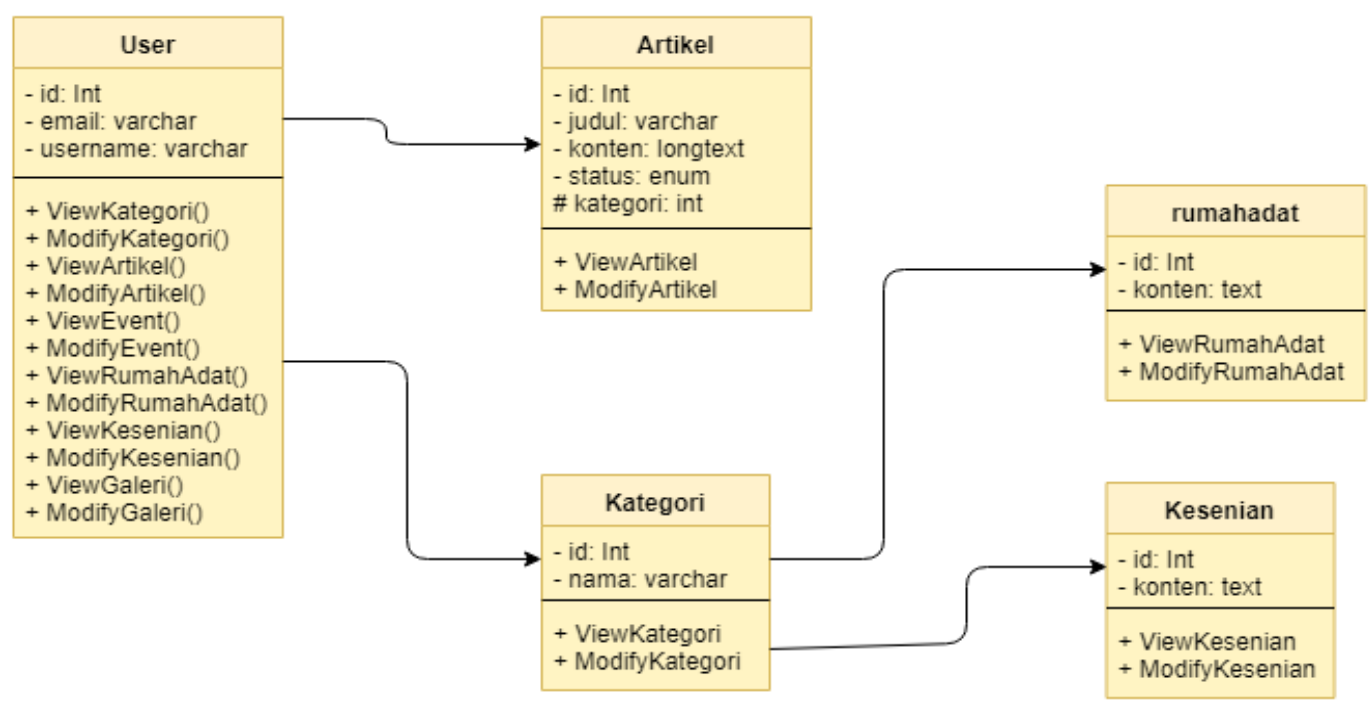

Gambar 4. Class diagram

\section{3) Class Diagram}

Adapun class diagram yang digunakan seperti pada Gambar 4.

\section{Tampilan Website}

Berikut merupakan beberapa capture dari website yang dirancang diperlihatkan pada Gambar 5, Gambar 6 dan Gambar 7 [11].

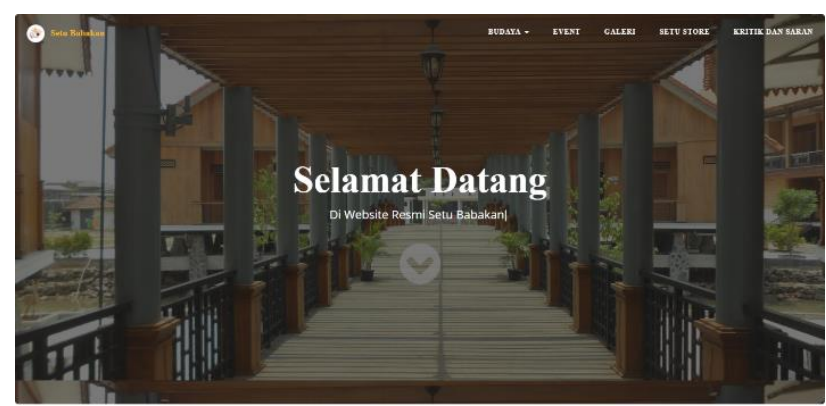

Gambar 5. Halaman utama website

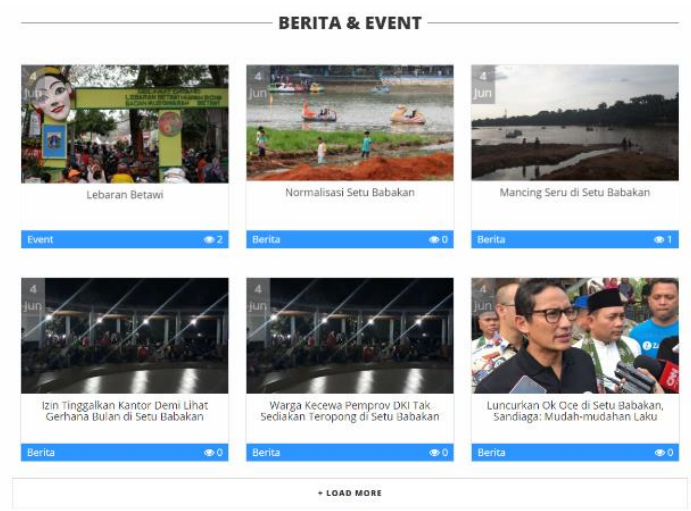

Gambar 6. Halaman artikel
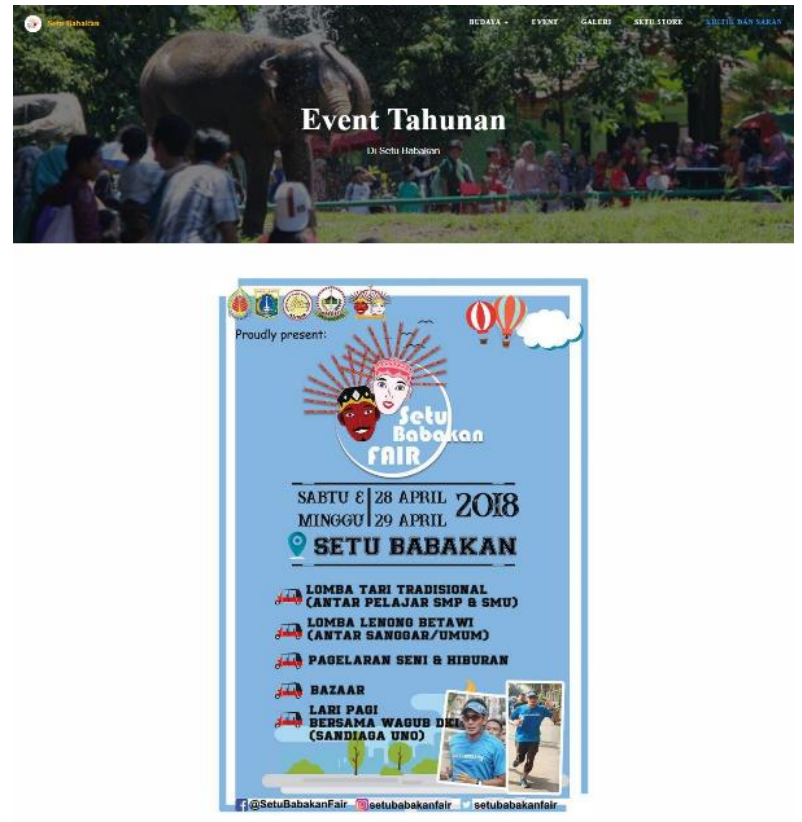

Gambar 7. Halaman event

Halaman dashboard admin dapat dilihat pada Gambar 8. merupakan fitur untuk admin yang digunakan dalam pengelolaan data website.

\section{Pengujian Sistem}

Pengujian dilakukan menggunakan blackbox testing terhadap jenis peramban (browser) yang digunakan [12]. 


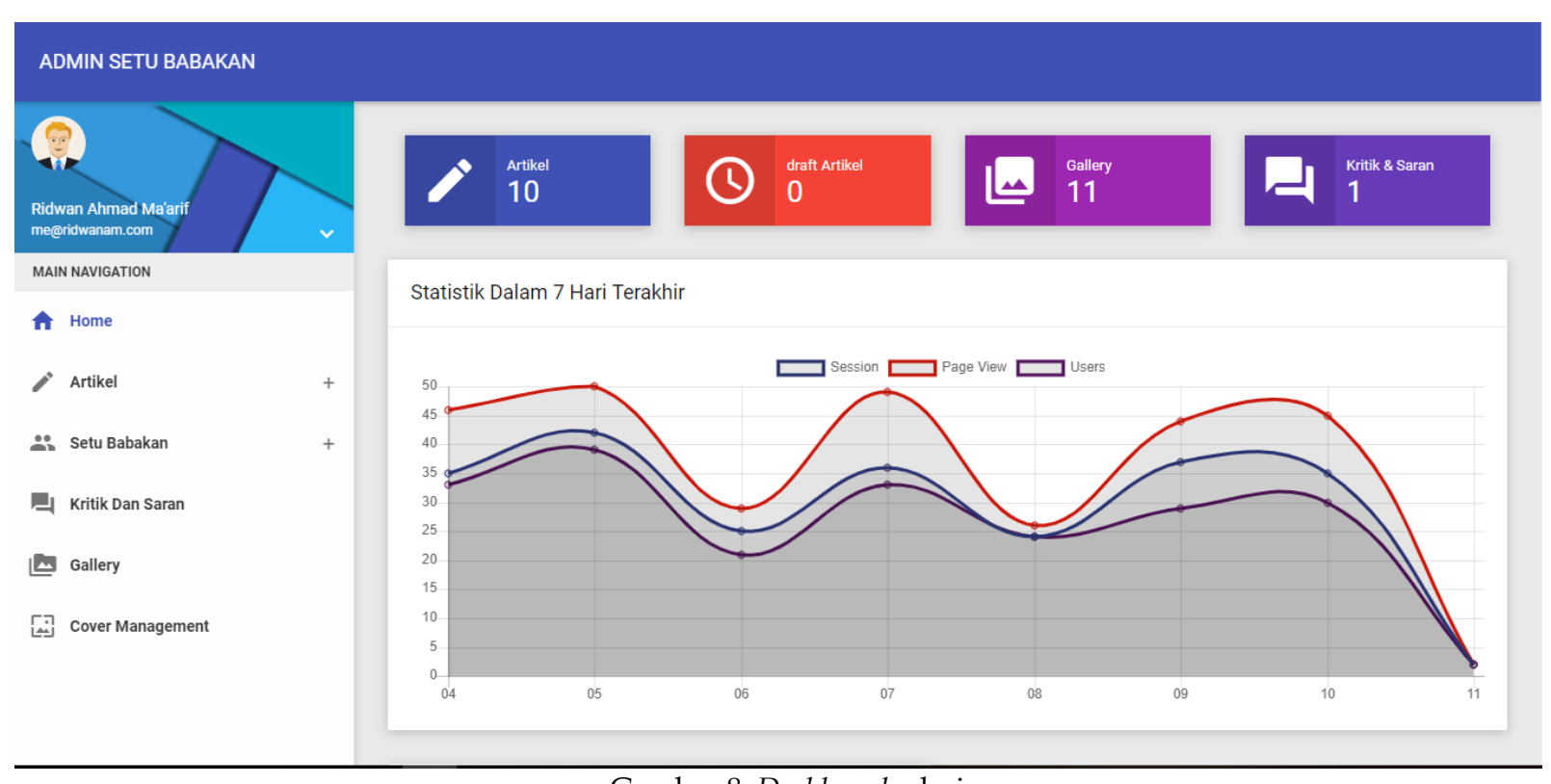

Gambar 8. Dashboard admin

Tabel 1. Pengujian website terhadap jenis peramban yang digunakan

\begin{tabular}{|c|c|c|}
\hline Browser/Versi & Hasil & Keterangan \\
\hline $\begin{array}{l}\text { Microsoft Edge/ } \\
42.17134 .1 .0\end{array}$ & $\begin{array}{l}\text { Dapat diakses } \\
\text { sesuai fungsi }\end{array}$ & Berhasil \\
\hline $\begin{array}{l}\text { Mozilla Firefox/ } \\
67.0 .4\end{array}$ & $\begin{array}{l}\text { Dapat diakses } \\
\text { sesuai fungsi }\end{array}$ & Berhasil \\
\hline $\begin{array}{l}\text { Internet Explorer/ } \\
11.829 .17134 .0\end{array}$ & $\begin{array}{l}\text { Dapat diakses } \\
\text { sesuai fungsi }\end{array}$ & Berhasil \\
\hline $\begin{array}{l}\text { Google Chrome/ } \\
75.0 .3770 .100\end{array}$ & $\begin{array}{l}\text { Dapat diakses } \\
\text { sesuai fungsi }\end{array}$ & Berhasil \\
\hline
\end{tabular}

Hasil dalam pengujian Tabel 1 dapat berupa pernyataan;

a. Berhasil, mengartikan bahwa sistem berhasil diakses dalam jenis browser yang diujikan.

b. Gagal, mengartikan bahwa sistem tidak dapat diakses dalam jenis browser yang diujikan.

Selain itu pengujian juga dilakukan guna melihat kesesuaian fungsi dari setiap interface yang telah dirancang [13].
Tabel 2. Pengujian sistem terhadap fungsi interface

\begin{tabular}{cll}
\hline No. & \multicolumn{1}{c}{ Interface } & Hasil \\
\hline 1 & Form Utama & Berfungsi \\
2 & Form Galeri & Berfungsi \\
3 & Form Artikel & Berfungsi \\
4 & Form Kritik \& Saran & Berfungsi \\
5 & Form Event & Berfungsi \\
6 & Form Budaya & Berfungsi \\
7 & Dashboard Admin & Berfungsi \\
8 & Input Artikel & Berfungsi \\
9 & Input Galeri & Berfungsi \\
10 & Input Event & Berfungsi \\
11 & Input Budaya & Berfungsi \\
12 & Menerima Kritik \& Saran & Berfungsi \\
\hline
\end{tabular}

Hasil dalam pengujian Tabel 2 dapat berupa pernyataan:

a. Berfungsi, mengartikan bahwa fungsi interface yang diujikan telah sesuai dengan fungsinya.

b. Tidak berfungsi, mengartikan bahwa fungsi interface yang diujikan belum berfungsi seutuhnya.

Pada dua pengujian yang dapat dilihat pada Tabel 1 dan Tabel 2 menghasilkan keberhasilan 100\% pada keduanya. 


\section{KESIMPULAN}

Permasalahan dalam penelitian ini merupakan pengenalan kebudayaan betawi yang kurang terekspos, hal itu dapat diselesaikan salah satunya melalui perancangan sistem informasi berbasis website. Berdasarkan perancangan sistem yang dibangun menggunakan metode waterfall telah memenuhi kebutuhan pengguna, baik itu admin maupun pengunjung website.

Pengujian dalam penelitian ini menghasilkan keberhasilan $100 \%$ dalam mengakses website diberbagai browser dan juga keberhasilan fungsi dari berbagai jenis interface yang dibangun.

\section{DAFTAR PUSTAKA}

[1] A. D. Riyanto, "Hootsuite (We are Social): Indonesian Digital Report 2019," andi.link, 2019. [Online].

Available:

https://andi.link/hootsuite-we-are-socialindonesian-digital-report-2019/. [Accessed: 04Jul-2019].

[2] Rudi, "Setu Babakan, Benteng Terakhir Budaya Betawi di Tanah Betawi," NativeIndonesia, 2019. [Online]. Available: https://www.nativeindonesia.com/setubabakan/. [Accessed: 10-Jul-2019].

[3] A. Christian, S. Hesinto, and A. Agustina, "Rancang Bangun Website Sekolah Dengan Menggunakan Framework Bootstrap (Studi Kasus: SMP Negeri 6 Prabumulih)," J. SISFOKOM (Sistem Inf. dan Komputer), vol. 7, no. 1, p. 22, 2018.

[4] I. Sommerville, Software Engineering (Rekayasa Perangkat Lunak). Jakarta: Erlangga, 2011.

[5] M. Destiningrum and Q. J. Adrian, "Sistem Informasi Penjadwalan Dokter Berbasis Web Dengan Menggunakan Framework Codeigniter
(Studi Kasus: Rumah Sakit Yukum Medical Centre)," J. TEKNOINFO, vol. 11, no. 2, pp. 3037, 2015.

[6] A. S. Riyadi, E. Retnandi, and A. Deddy, "Perancangan Sistem Informasi Berbasis Website Subsistem Guru di Sekolah Pesantren Persatuan Islam 99 Rancabango," J. Algoritm., vol. 09, no. 40, 2012.

[7] I. D. Lesmono, "Rancang Bangun Sistem Informasi Penjualan Sepatu Berbasis Website Dengan Metode Waterfall," J. SWABUMI, vol. 6, no. 1, pp. 55-62, 2018.

[8] P. S. Hasugian, "Perancangan Website Sebagai Media Promosi Dan Informasi," J. Inform. Pelita Nusant., vol. 3, no. 1, pp. 82-86, 2018.

[9] Y. Trimarsiah and M. Arafat, "Analisis dan Perancangan Website Sebagai Sarana Informasi Pada Lembaga Bahasa Kewirausahaan dan Komputer AKMI Baturaja," J. Ilm. MATRIK, vol. 19, no. 1, pp. 1-10, 2017.

[10] A. Simangunsong, "Sistem Informasi Pengarsipan Dokumen Berbasis Web," J. Mantik Penusa, vol. 2, no. 1, pp. 11-19, 2018.

[11] D. Pranata, H. Hamdani, and D. M. Khairina, "Rancang Bangun Website Jurnal Ilmiah Bidang Komputer (Studi Kasus: Program Studi Ilmu Komputer Universitas Mulawarman)," J. Inform. Mulawarman, vol. 10, no. 2, p. 25, 2015.

[12] M. Susilo, R. Kurniati, and Kasmawi, "Rancang Bangun Website Toko Online Menggunakan Metode Waterfall," J. Nas. Inform. dan Teknol. Jar., vol. 2, no. 1, pp. 73-78, 2017.

[13] S. Prabowo, "Rancang Bangun Website Untuk Layanan Jasa Kuliner," Universitas Muhammadiyah Surakarta, 2016. 